\title{
Caracterização histomorfológica da atrofia inflamatória proliferativa na próstata canina
}

\author{
Histomorphological characterization of proliferative inflammatory atrophy in canine prostate
}

\author{
Denise Caroline Toledo ${ }^{\mathrm{I}}$ Mariana Batista Rodrigues Faleiro ${ }^{\mathrm{II}}$ \\ Marcela Marcondes Pinto Rodrigues ${ }^{\mathrm{III}}$ Giovana Wingeter Di Santis ${ }^{\mathrm{IV}}$ \\ Renée Laufer Amorim ${ }^{\mathrm{V}}$ Veridiana Maria Brianezi Dignani de Moura ${ }^{\mathrm{VI}}$
}

\section{RESUMO}

A atrofia inflamatória proliferativa (PIA) é uma lesão prostática pré-maligna de grande ocorrência na próstata humana e, mais recentemente, também observada em cães. Esta pesquisa teve por objetivo verificar os aspectos histomorfológicos da PIA na próstata canina. Foram utilizadas 43 próstatas de cães adultos, de várias raças e portes, e com histórico ou não de doença prostática. Os focos de PIA apresentaram epitélio displásico, formado por ácinos atróficos e com mais de uma camada de células de morfologia atípica, especialmente anisocitose, anisocariose, citoplasma reduzido, núcleo volumoso e com nucléolo evidente. As alterações epiteliais eram sempre acompanhadas de infiltrado inflamatório intersticial periacinar predominantemente linfocitário. Foi observado um índice de 65\% de PIA. Destes, $39 \%$ corresponderam à PIA com infiltrado inflamatório discreto, $42 \%$ à PIA com infiltrado moderado e $19 \%$ à PIA com infiltrado acentuado. Dessa forma, foi possível caracterizar a PIA prostática canina e constatar alta ocorrência dessa alteração nos cães examinados. Considera-se de grande importância a caracterização histomorfológica da PIA em cães, já que essa lesão vem sendo estudada na próstata humana quanto ao potencial pré-maligno. Ressalta-se ainda a possibilidade de utilização da próstata do cão como modelo experimental da PIA humana, considerando a semelhança dessa afecção prostática em ambas as espécies.

Palavras-chave: cão, PIA, displasia prostática.

\begin{abstract}
Proliferative inflammatory atrophy (PIA) is a premalignant prostatic change with high occurrence in human prostate and it has been recently observed in dogs. This research aimed to verify the morphologic aspects of the PIA in canine prostate. It was studied 43 glands of adult dogs of several breeds and sizes and with or without a history of prostatic disease. PIA focus was characterized by dysplastic epithelium, atrophic acini formed by several layers of cells with variable degrees of anisocytosis, anisokaryosis, reduced amount of cytoplasm and nuclei with prominent nucleoli. The epithelial changes were always accompanied by periacinar interstitial infiltrate composed of mononuclear cells, especially lymphocytes. The histomorphological evaluation showed occurrence of $65 \%$ of PIA. Out of these, $39 \%$ were PIA with discrete inflammatory infiltration, 42\% PIA with moderate infiltrate and 19\% PIA with marked infiltration. Thus, it was possible to characterize the PIA in the canine prostate which had high occurrence. The histomorphological characterization of canine PIA is considered of great importance because the premalignant characteristic of it have been studied in human prostate. The canine prostate can be used as an experimental model of human PIA, because the lesion is similar in both species.
\end{abstract}

Key words: $\operatorname{dog}$, PIA, prostatic dysplasia.

\footnotetext{
'Curso de Medicina Veterinária, Escola de Veterinária (EV), Universidade Federal de Goiás (UFG), Goiânia, GO, Brasil.

"Programa de Pós-graduação em Ciência Animal, Área de Patologia Animal, EV, UFG, Goiânia, GO, Brasil.

IIIPrograma de Pós-graduação em Medicina Veterinária, Área de Patologia Animal, Faculdade de Medicina Veterinária e Zootecnia (FMVZ), Universidade Estadual Paulista (UNESP), Botucatu, SP, Brasil.

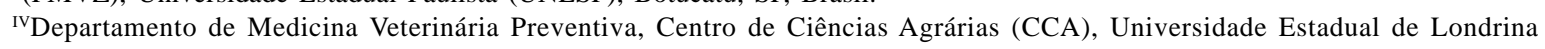
(UEL), Londrina, PR, Brasil.

v'Serviço de Patologia Veterinária, Departamento de Clínica Veterinária, FMVZ, UNESP, Botucatu, SP, Brasil.

${ }^{{ }^{V}}$ Setor de Patologia Animal, Departamento de Medicina Veterinária, EV, UFG. Estrada do Campus s/no , Campus II, 74001-970, CP 131, 74001-970, Goiânia, GO, Brasil. E-mail: vdmoura@vet.ufg.br. Autor para correspondência.
} 


\section{INTRODUÇÃO}

A próstata canina tem sido tema de vários estudos nas últimas décadas, o que não se justifica apenas pela alta incidência de afecções que a acometem, mas também pelas similaridades com a próstata humana (DE MARZO et al., 1999). Algumas lesões prostáticas são estudadas quanto ao seu potencial pré-maligno, como a atrofia inflamatória proliferativa (proliferative inflammatory atrophy ou PIA), seja por similaridades morfológicas com o câncer ou por envolverem fatores potencialmente carcinogênicos (DE MARZO et al., 2006).

A PIA é uma lesão do epitélio prostático que ocorre simultaneamente a diferentes graus de inflamação intersticial adjacente, sendo observada com alta frequência na próstata humana (DE MARZO et al., 1999) e também descrita na próstata canina (RODRIGUES, 2007; DI SANTIS, 2007). O termo PIA foi proposto por DE MARZO et al. (1999) para designar focos de epitélio glandular proliferativo com o aspecto morfológico de atrofia simples ou hiperplasia pósatrófica (PAH), ocorrendo em associação à inflamação. Os mesmos autores explicam que apesar da proliferação, a lesão não cresce em volume devido a uma possível perda celular que compensa a proliferação. Além disso, esses autores acreditam que o epitélio em regeneração suprima a morte celular programada, ao menos temporariamente, para substituir as células perdidas, o que embasa o conceito de que a PIA é uma lesão regenerativa.

PUTZI \& DE MARZO (2000) acreditam que a PIA possa representar um precursor da neoplasia intraepitelial prostática (PIN) e/ou do carcinoma prostático. Segundo DE MARZO et al. (2003), todas as formas de atrofia focal da próstata são proliferativas, e a ampla maioria está associada à inflamação, de maneira que essas lesões podem se originar em um cenário de estresse oxidativo aumentado, possivelmente derivado das células inflamatórias adjacentes.

Em trabalhos anteriores, foi constatado um grande número de próstatas caninas apresentando inflamação aguda ou crônica em associação topográfica com focos de atrofia glandular, acompanhados de células epiteliais atípicas (LAUFER AMORIM, 2001; DE MOURA, 2004), o que enfatiza a importância da caracterização dessas lesões na glândula do cão. Nesse contexto, o presente estudo teve como objetivo a caracterização histomorfológica da PIA na próstata canina.

\section{MATERIAL E MÉTODOS}

Foram utilizadas 43 próstatas de cães adultos, de várias raças e de vários portes, com ou sem histórico de doença prostática. O material foi fixado em formol tamponado a $10 \%$, por 48 horas e, na sequência, mantido em álcool $70^{\circ}$, até o processamento histológico de rotina e a coloração pela hematoxilina e eosina. A avaliação foi realizada a partir de um fragmento da porção medial de cada próstata contento os dois lobos. A caracterização histomorfológica dos focos de PIA foi realizada por dois observadores separadamente, de acordo com critérios adaptados de DE MARZO et al. (2006) e DI SANTIS (2007). Foi considerada a presença de epitélio prostático displásico, caracterizado por ácinos de tamanhos e formas variáveis e compostos por mais de uma camada de células epiteliais atípicas distintas e com morfologia anormal, como citoplasma marcadamente reduzido e hipocromático, núcleo volumoso e um ou mais nucléolos evidentes. As alterações epiteliais displásicas foram consideradas PIA quando obrigatoriamente acompanhadas de infiltrado inflamatório mononuclear intersticial adjacente, que foi classificado em discreto, moderado e acentuado.

A avaliação histológica foi realizada em microscópio óptico com o uso do menor aumento (32x), seguido dos aumentos subsequentes (100x, 250x e 400x). O aumento de 32x auxiliava na visualização global do material, permitindo identificar áreas com diferentes padrões de lesão. Nos demais aumentos, avaliaram-se as estruturas epitelial e estromal e o infiltrado inflamatório. O aumento de 400x foi utilizado para a avaliação dos aspectos celulares. Ao final da análise do material, obteve-se a ocorrência de PIA isoladamente, sendo a estatística descritiva a forma de análise e apresentação dos resultados.

\section{RESULTADOS}

Na avaliação histomorfológica das 43 próstatas, foram encontradas 28 glândulas (65\%) com focos de PIA e 15 (35\%) com aspecto histológico normal ou com outro tipo de alteração prostática, como hiperplasia prostática benigna (HPB), neoplasia intraepitelial prostática (PIN) e carcinoma prostático. Os focos de PIA foram observados isoladamente ou em concomitância com HPB, PIN e carcinoma prostático.

Com relação à raça, 71\% das amostras prostáticas com PIA eram de cães sem raça definida (SRD), 18\% de Pit Bull, 7\% de Poodle e 4\% de Sharpei.

Nas 28 glândulas com lesões histomorfológicas características de PIA, foram 
identificados 193 focos dessa alteração. Destes, 75 (39\%) eram acompanhados de infiltrado inflamatório discreto, composto por células mononucleares intersticiais esparsas; 81 (42\%) apresentaram infiltrado moderado, com agregados de células mononucleares intersticiais; e 37 (19\%) eram acompanhados de infiltrado acentuado, com agregados confluentes de leucócitos mononucleares associados à formação de folículos linfoides. Na figura 1, estão representados os aspectos histomorfológicos de uma próstata canina normal e com os diferentes tipos de PIA.

O infiltrado leucocitário observado nos focos de PIA era composto de células mononucleares, principalmente linfócitos, alguns plasmócitos e macrófagos, e raramente neutrófilos. As áreas de infiltrado foram observadas especialmente no interstício e raramente no epitélio prostático.

Os focos de PIA observados eram caracterizados por epitélio displásico circundado por tecido de morfologia normal. Os ácinos apresentavam formas e tamanhos variados, sendo frequentemente reduzidos e com formato angular. Eram formados por mais de uma camada de células epiteliais distintas, e estas apresentavam características atípicas, como citoplasma marcadamente reduzido, tanto na região lateral como na apical, núcleo volumoso e com nucléolos evidentes (Figura 2), anisocitose e anisocariose. Essa lesão era sempre acompanhada de infiltrado inflamatório periacinar predominantemente linfocitário.

As lesões características de PIA foram encontradas desde as adjacências da uretra até o parênquima prostático pericapsular da porção medial da próstata, e não foi observada maior ocorrência em uma ou outra área dos cortes.

\section{DISCUSSÃO}

A atrofia da próstata é identificada pela redução do volume glandular e do estroma préexistentes e pode ser dividida em dois padrões: difuso e focal. A atrofia difusa resulta da diminuição de andrógenos circulantes e envolve a próstata como um todo, de maneira uniforme (DE MARZO et al., 1999; JOHNSTON et al., 2000). Já a atrofia focal não está relacionada à diminuição de andrógenos circulantes e ocorre como áreas de epitélio atrófico intercaladas com áreas de epitélio de aspecto normal e são proliferativas, e a maioria está associada à inflamação (DE MARZO et al., 1999; DE MARZO et al., 2006).

Na próstata humana, o termo atrofia inflamatória proliferativa (PIA) foi proposto para designar focos de epitélio glandular displásico e proliferativo com o aspecto morfológico de atrofia focal simples e inflamação concomitante (DE MARZO et al., 1999). Os resultados deste estudo confirmam a PIA em cães, já que as lesões observadas na próstata dos animais apresentaram morfologia semelhante à descrita para PIA na próstata humana (DE MARZO et al., 2006). Ressalta-se que apenas DI SANTIS (2007) e RODRIGUES (2007) descreveram lesão similar à PIA em seus trabalhos acadêmicos envolvendo a glândula canina e DELELLA et al. (2010), em estudo com próstata de ratos.

Embora o objetivo deste estudo envolva apenas a caracterização histomorfológica da PIA na próstata canina, destaca-se a importância da avaliação mais detalhada dessa alteração na próstata desses animais, já que, na glândula humana, a PIA tem sido avaliada quanto ao seu potencial pré-maligno (PUTZI \& DE MARZO, 2000; PALAPATTU et al., 2004; DE MARZO et al., 2006). Nesse contexto, DI SANTIS (2007) avaliou alguns aspectos imunológicos da PIA no cão e encontrou elevado índice proliferativo, indiferenciação de células secretoras e perda de expressão para E-caderina, concluindo que a lesão apresenta algumas características observadas em lesões com potencial pré-maligno, como a neoplasia intraepitelial prostática (PIN).

Neste estudo, outra observação importante referente à análise histológica da próstata canina foi a presença simultânea de PIA e outras lesões prostáticas como a hiperplasia prostática benigna (HPB), a PIN e o carcinoma, reiterando os achados de DI SANTIS (2007) e RODRIGUES (2007). Considerando a possibilidade de a PIA no cão representar uma lesão pré-neoplásica, como já é descrito para essa lesão na próstata humana (PALAPATTU et al., 2004; DE MARZO et al., 2006; TOMAS et al., 2007), apenas a concomitância com lesões como a PIN e o carcinoma não é suficiente para afirmar que a PIA possui potencial pré-maligno. Segundo VIS \& VAN DER KWAST (2001), vários critérios devem ser considerados na caracterização de uma lesão pré-maligna, como relação epidemiológica, presença anterior ao câncer, semelhanças morfológicas e imunológicas e proximidade ou equivalência às suas presunções de malignidade. Assim, a partir da classificação histomorfológica, são necessários mais estudos sobre a PIA canina para verificar o comportamento biológico dessa lesão e concluir algo acerca do seu potencial pré-maligno.

TOMAS et al. (2007) relatam que, na PIA, o infiltrado consiste de linfócitos e variado número de macrófagos. Já DE MARZO et al. (1999) descrevem que os linfócitos são as principais células inflamatórias que acompanham essa lesão, mas há possibilidade de 


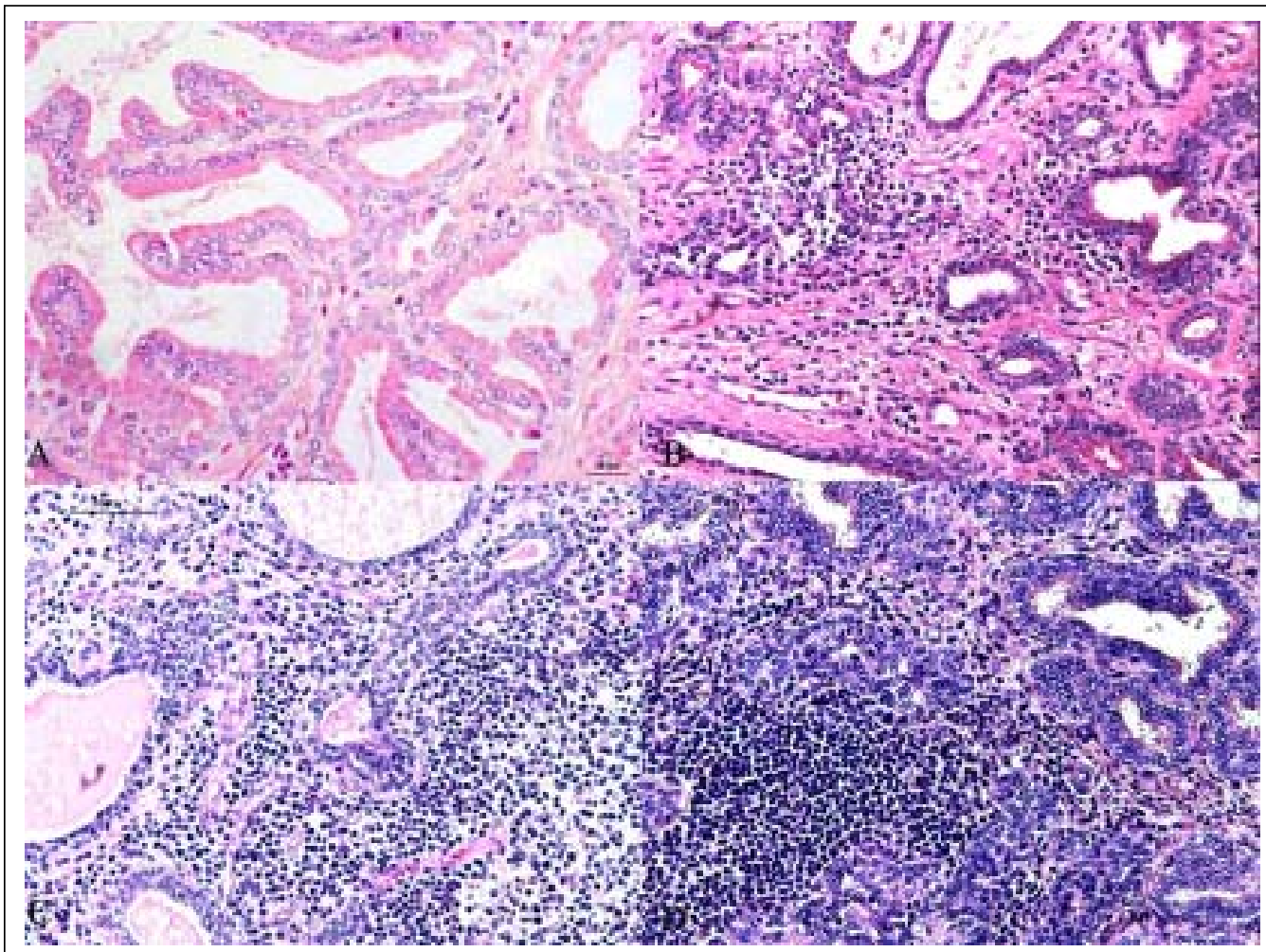

Figura 1 - Fotomicrografia prostática canina. A) Histomorfologia normal. Epitélio com uma única camada de células cúbicas e colunares, sustentado por delicado estroma fibrovascular. B) PIA discreta. Ácinos atróficos e células inflamatórias intersticiais esparsas. C) PIA moderada. Atrofia acinar e agregados de células mononucleares. D) PIA acentuada. Predominância de linfócitos intersticiais dispostos em folículos. HE.

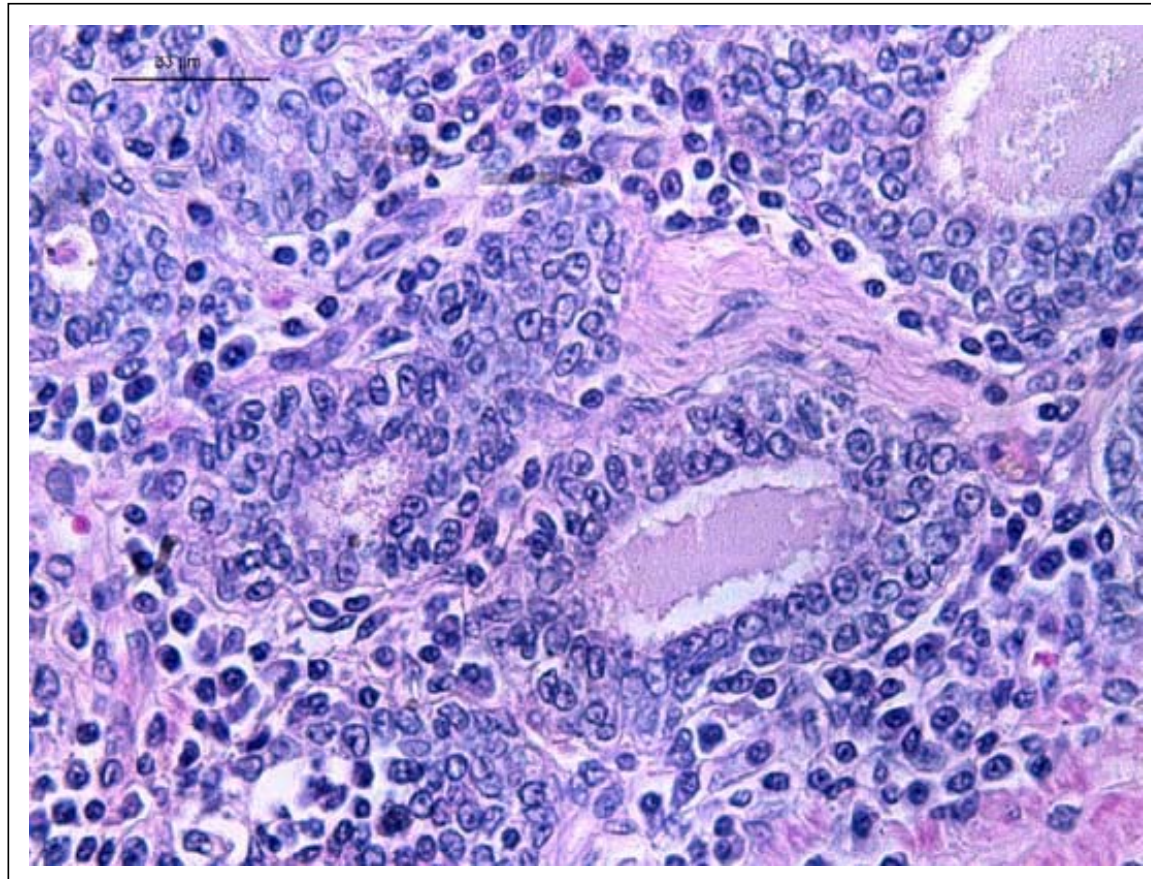

Figura 2 - Fotomicrografia prostática canina. PIA. Infiltrado inflamatório e atipia epitelial. Mais de uma camada de células epiteliais, citoplasma marcadamente reduzido, núcleos aumentados e nucléolos evidentes. HE. 
infiltrado polimorfonuclear concomitante. Neste estudo, em todos os focos de PIA canina, independente da intensidade, o infiltrado inflamatório intersticial periacinar era predominantemente linfocítico. Em relação à atrofia e inflamação, DE MARZO et al. (2006) descrevem que todas as formas de atrofia focal da próstata são proliferativas, e a maioria está associada à inflamação. Dessa maneira, essas lesões podem se originar em um cenário de estresse oxidativo aumentado, possivelmente derivado das células inflamatórias próximas (MATTOS, 1999; PALAPATTU et al., 2004; DE MARZO et al., 2006; SUGAR, 2006).

Sabe-se que a inflamação é capaz de incitar a carcinogênese por causar dano celular e no genoma, promover a substituição celular e criar um microambiente rico em citocinas e fatores de crescimento que podem elevar a replicação celular, a angiogênese e o reparo tecidual. Considerando essa teoria e a característica inflamatória da PIA, reitera-se a importância de estudos mais específicos sobre o comportamento biológico dessa lesão na próstata canina, já que regiões de PIA da próstata humana que são inábeis em eliminar o dano oxidativo causado pela inflamação ao genoma podem progredir para PIN ou câncer prostático (PALAPATTU et al., 2004). Ainda, se a PIA canina for semelhante à humana, além dos aspectos histomorfológicos, é possível que a espécie seja útil como modelo experimental também para essa afecção prostática, como ocorre com a HPB.

Segundo DE MARZO et al. (1999) e PLATZ \& DE MARZO (2004), a PIA pode ser observada concomitantemente a diferentes graus de inflamação adjacente na próstata humana; contudo, não classificam a lesão de acordo com a intensidade do infiltrado inflamatório. Já RODRIGUES (2007) e DI SANTIS (2007) classificam a PIA na glândula canina de acordo com as alterações epiteliais e com a intensidade do infiltrado leucocitário adjacente, sendo esse critério utilizado na caracterização da PIA neste estudo. No que se refere a esse aspecto, acredita-se que a determinação da intensidade do infiltrado tenha importância no futuro, pois, caso seja comprovada a relação entre a inflamação intersticial adjacente e as modificações celulares que ocorrem no epitélio prostático, a mensuração do infiltrado pode ser válida. Além disso, apesar de haver informação na literatura de que o infiltrado leucocitário pode ser encontrado tanto no epitélio como no estroma (DE MARZO et al., 1999; DE MARZO et al., 2006), neste trabalho, o infiltrado foi predominante no componente estromal.

RODRIGUES (2007) caracteriza histomorfologicamente a PIA como uma lesão onde há proliferação de células epiteliais glandulares que apresentam atipias, como núcleo volumoso, nucléolos evidentes e citoplasma escasso, associado a infiltrado inflamatório mononuclear, assim como observado neste estudo. Alguns autores relatam que os focos de PIA apresentam aparência hipercromática global das glândulas envolvidas (DE MARZO et al., 1999; DI SANTIS, 2007); entretanto, essa característica não foi visualizada nos focos de PIA caracterizados nesta pesquisa.

A PIA pode ser definida como focos de atipias epiteliais associadas à atrofia glandular focal, bem como à inflamação aguda ou crônica (DE MARZO et al., 2006), assim como observado no presente estudo. TOMAS et al. (2007) relatam que a ocorrência de PIA na próstata humana é mais frequente na zona periférica; apesar disso, na próstata canina, foram observados focos de PIA desde a região periuretral até a periférica, não havendo maior ocorrência em um ou outro segmento glandular.

DE MARZO et al. (2006) propuseram uma nova classificação para as atrofias prostáticas, considerando quatro padrões arquiteturais: atrofia simples, atrofia simples com formação de cistos, hiperplasia pós-atrófica e atrofia parcial. Quando mais de um tipo é encontrado, a lesão é considerada mista. Os autores incluíram ainda, de forma mais genérica, os termos atrofia inflamatória proliferativa (PIA) e atrofia proliferativa (PA) para designar lesões atróficas focais, com aumento do índice proliferativo, nas quais a inflamação esteja presente ou ausente, respectivamente. Para os subtipos atrofia simples com formação de cistos e atrofia parcial, ainda permanece indeterminado se há aumento no índice proliferativo, portanto tais subtipos não são atualmente considerados PIA ou PA, apenas hiperplasia pósatrófica e atrofia simples. Nesse contexto, foram constatadas diferenças entre as próstatas canina e humana, já que, na glândula canina, não foi possível determinar os subtipos de PIA. Apesar disso, é possível reconhecer a legitimidade dessa alteração no tecido prostático canino, sendo, portanto, de grande valia o estudo do seu comportamento e sua evolução, visto que, na espécie humana, é considerada precursora do câncer prostático.

\section{CONCLUSÃO}

Foi possível caracterizar a PIA na próstata canina, sendo alta a sua ocorrência. Além disso, considera-se a caracterização histomorfológica da PIA na próstata canina de grande importância devido ao fato da lesão ser considerada pré-maligna na próstata humana, o que atenta para o estudo da gênese das 
neoplasias prostáticas caninas. Ressalta-se ainda a possibilidade de utilização da próstata canina como modelo experimental da PIA humana, já que a lesão é semelhante em ambas as espécies.

\section{AGRADECIMENTOS}

Ao Conselho Nacional de Desenvolvimento Científico e Tecnológico (CNPq), pela concessão de bolsa de iniciação científica. À Fundação de Amparo à Pesquisa do Estado de São Paulo (FAPESP), pelo auxílio à pesquisa $-08 / 54052-3$.

\section{REFERÊNCIAS}

DELELLA, F.K. et al. Finasteride treatment alters MMP-2 and -9 gene expression and activity in the rat ventral prostate. International Journal of Andrology, Copenhagen, v.33, n.1, p.114-122, 2010. Disponível em: <http://www3.interscience.wiley.com/cgi-bin/fulltext/ 122443383/PDFSTART>. Acesso em: 25 maio, 2010. doi:10.1111/ j.1365-2605.2009.00970.x.

DE MARZO, A.M. et al. Proliferative inflammatory atrophy of the prostate: Implications for prostatic carcinogenesis. American Journal of Pathology, v.155, n.6, p.1985-1992, 1999. Disponível em: <http://aip.amjpathol.org/cgi/reprint/ 155/6/1985>. Acesso em: 25 maio, 2010. doi:10.1111/j.13652605.2009.00970.x.

DE MARZO, A.M. et al. Human prostate câncer precursors and pathobiology. Urology. v.62, n.5, supl.1, p.55-62, 2003. Disponível em: <http://www.sciencedirect.com/ science?_ob=MImg\&_imagekey=B6VJW-49X23NS-8-

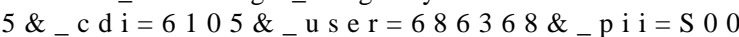
$90429503010173 \&$ \&_orig = se arch \&_coverDate =11\%2F30\%2F2003\&_sk=999379994.8998\&view=c\&wchp=dGLzVzzzSkWb\&md5=7f6abfd8132f17f9ad513bb6a5cc63cd\&ie=/ sdarticle.pdf $>$. Acesso em: 25 maio, 2010. doi:10.1016/ j.urology.2003.09.053.

DE MARZO, A.M. et al. A working group classification of focal prostate atrophy lesions. American Journal of Surgical Pathology, v.30, n.10, p.1281-1291, 2006. Disponível em: < h t t p : / / journals. l w w . com/ajs p/page s/ a r i c l e vie wer.as p x ? y a r $=2006$ \& ssue $=10000 \&$ article $=00011 \&$ type $=$ abstract $>$. Acesso em: 25 maio, 2010. doi: 10.1097/01.pas.0000213289.50660.be.

DE MOURA, V.M.B.D. Estudo laboratorial, anatomopatológico, e imunoistoquímico da próstata de cães adultos. 2004. 144f. Tese (Doutorado em Patologia Animal) - Universidade Estadual Paulista "Julio de Mesquita Filho", Jaboticabal, SP.
DI SANTIS, G.W. Padrão histopatológico, perfil imunoistoquímico e potencial pré-maligno das lesões displásicas da próstata canina. 2007. 114f. Tese (Doutorado em Patologia Animal) - Faculdade de Medicina Veterinária e Zootecnia, Universidade Estadual Paulista, Botucatu, SP.

JOHNSTON, S.D. et al. Prostatic disorders in the dog. Animal Reproduction Science, v.60, p.405-415, 2000. Disponível em: <http:/ /www.sciencedirect.com/science?_ob=MImg\&_imagekey=B6T4340F1PVW-14-3\&_cdi $=4963 \&$ \&_user $=686368 \&$ \&ii $=$ S 0378432000001019 \&_orig = s e a r c h \&_c o ve r D a t e $=0 \begin{array}{lllllllllllll} & 7 \% & 2 & \mathrm{~F} & 0 & 2 & \% & 2 & \mathrm{~F} & 2 & 0 & 0 & 0\end{array}$ \& $\mathrm{s} \mathrm{k}=999389999 \& \mathrm{v}$ i e w $=\mathrm{c} \& \mathrm{w} \mathrm{ch} \mathrm{p}=\mathrm{d}$ G L b V l W zSkWA\&md5=032e9402617bf9044b57ecb2bf8dcb08\&ie=/ sdarticle.pdf $>$. Acesso em: 25 maio, 2010. doi: 10.1016/S03784320(00)00101-9.

LAUFER AMORIM, R. Estudo clínico, laboratorial e anatomoátológico das próstatas de cães adultos. 2001. 116f. Tese (Doutorado em Clínica Veterinária) - Universidade Estadual Paulista “Julio de Mesquita Filho”, Jaboticabal, SP.

MATTOS, M.C.F.I. Transtornos do crescimento e da diferenciação celular. In: MONTENEGRO, M.R.; FRANCO, M. Patologia: processos gerais. 4.ed. São Paulo: Atheneu, 1999. p. 209-222.

PALAPATTU, G.S. et al. Prostate carcinogenesis and inflammation: emerging insights. Carcinogenesis, v.26, n.7, p.1170-1181, 2004. Disponível em: <ftp://www.cohensw.com/ pub/pca/inflammation/palapattu_etal_carcinogenesis_2004.pdf $>$. Acesso em: 25 maio, 2010. doi:10.1093/carcin/bgh317.

PLATZ, E.A.; DE MARZO, A.M. Epidemiology of inflammation and prostate cancer. Journal of Urology, v.171, p.S36-S40, 2004. Disponível em: <http://www.sciencedirect.com/ science?_ob=MImg\&_imagekey=B7XMT-4HG4W5N-D$1 \&$ \&_di $=29679 \&$ \&user $=686368 \&$ \&_pii $=$ S00225347056251 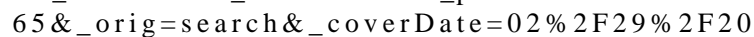 $04 \&$ \&k=998289997.8998\&view $=$ c \& w chp $=$ dGLzVzzzSkzS\&md5=0c322c6445f793ab1e6db4e837911c24\&ie=/ sdarticle.pdf $>$. Acesso em: 25 maio, 2010. doi: 10.1097/ 01.ju.0000108131.43160.77.

PUTZI, M.J.; DE MARZO, A.M. Morphologic transitions between proliferative inflammatory atrophy and high-grade prostatic intraepithelial neoplasia. Urology, v.56, p.828-832, 2000. Disponível em: <http://www.sciencedirect.com/ science?_ob=MImg\&_imagekey=B6VJW-41JTP3Y-X5\&_cdi=6105\&_user $=686368 \&$ _ pii=S0090429500007767 \& orig = search \& c over D a t e $=11 \% 2$ F $30 \%$ 2F2000\&_sk=999439994\&view =c \&wchp=dGLbVlbzSkWb\&md5=1f7fa5fe6a68169b9c7fa5f15b3d8b2b\&ie=/ sdarticle.pdf $>$. Acesso em: 25 maio, 2010. 